EWA WILLIM

Kraków

\title{
ON THE FORM-FUNCTION DICHOTOMY IN LINGUISTIC THEORY
}

Keywords: form-function mismatches, formal and functional grounding of grammar, linguistic argumentation

\begin{abstract}
This paper focuses on an important divide in theoretical linguistics between two broad perspectives on the structural properties of human languages, generative and functionalist. In the former, linguistic structure is explained in terms of discrete categories and highly abstract principles, which may be language-independent or language-specific and purely formal or functional in nature. In the latter, explanation for why languages have the structure that they do is found 'outside' language, in the general principles of human cognition and the communicative functions of language. The aim of this paper is to highlight the need for abstractness, explicitness, simplicity and theoretical economy in linguistic description and explanation. The question is not whether principles of grammar are formal or functional. The question is whether the principles that are postulated to explain linguistic structure express true generalizations.
\end{abstract}

\section{Introduction}

A common view of language is that it is a coding system that links representations of sound (or, more generally, gesture) to representations of meaning. In approaches that take language to be a mental program, a state of the computational system of the mind / brain, the linguistic representations of, respectively, sound and meaning, are structured expressions that provide instructions for (at least) two systems external to language: the human sensorimotor apparatus and the human conceptual system 
(cf., among others, Chomsky 1995, 2005, 2007). The sensorimotor system converts the representations of sound into pronunciations and constructs them in processing sensory data. The human cognitive system uses the linguistic representations of meaning in thought processes, e.g. interpretation, categorization, inferencing, reasoning, problem-solving, planning, etc. ${ }^{1}$ The role of linguistic theory is to describe and explain the complexity of the language faculty, and in particular, to uncover the general principles and mechanisms that characterize the intricate computational system in the human mind that deals with linguistic data. Accordingly, generalizations about grammatical phenomena are captured in terms of structure-dependent constraints, some of which are innate and language-independent, characterize the initial state of the language faculty, Universal Grammar (UG), and are motivated by the properties of the language-external interfaces and principles of computational efficiency.

In a different theoretical perspective in linguistics, referred to as functionalist, there is a very close linkage between the structural properties of grammars and the cognitive and communicative needs of speakers. The close match between form and function in language follows automatically on the assumption that the structure of languages is "fundamentally informed by the structure of our experience and our cultural models of experience" (DeLancey 2001: 1). As grammar tailors itself to speakers' communicative needs, explanation of grammatical phenomena is functional in that linguistic form is not explained in terms of formal principles that do not make reference to discourse-related external factors but rather, it is explained in terms of interpretation in acts of linguistic behavior that derives from the context of communication (cf. Croft 1995).

In this paper, I will look at some of the claims that have been made regarding the relationship between the structural properties of language and the cognitive and communicative functions of language. The reminder is structured as follows: section 2 outlines some problems for the idea that language is mainly for providing representations of meaning and that all or much of the structure of language is derivative from semantics and human conceptualization. In section 3 , some effects stemming from the pressure for effective expression of thought in linguistic behavior are discussed. Section 4 concludes. ${ }^{2}$

While there is no denying that language and thought are intimately related, there is an ongoing debate about the precise relationship between language and abstract and productive human thought. See, e.g. Carruthers (2002) for an overview of the competing claims on the role of language in human cognition, which highlights some important dissociations between language, meaning and cognition whereby none can be entirely reduced to the other.

2 Due to space limitations, I will limit the discussion to the syntactic level of linguistic structure. However, structural complexity is not only the signature of syntax. Also natural language phonology has complex structure although as sounds are meaningless, the complex principles that account for the phonological structure of natural language have no grounding in mental representations of meaning or thought. The same can be said about morphology: there are complex structural means of creating complex meanings in the morphology, including affixation, compounding, conversion, reduplication, cliticization, internal modification, reduction, blending, etc. These means are not motivated by conceptual necessity: complex meanings can and do arise in the syntax. Having them also in morphology poses a computational burden. See Hurford (2002) for further discussion. 


\section{Formal properties of language and the cognitive function of language}

One way of looking at language is to take it to be primarily designed for facilitating cognition. On this view, language is designed to provide mental structures which capture the propositions (roughly, thoughts) that are expressed with sentences. Sentences are neither physical events nor physical objects but rather, they are abstract structures generated by structure-building principles, which are subject to constraints of computational efficiency, but which (may) make no reference to discourse-related external elements.

An alternative is to attribute the structural properties of language to the speakers' need for expression of thought, including verbal communication. On this view, as communication takes place in communicative contexts, the structural properties that sentences have are derivative from pragmatic, social and cultural principles of verbal communication.

Regardless the theoretical orientation, a system that is well designed for representation of thought need not necessarily be well designed for verbal communication (cf., among others, Newmeyer 2001, Hurford 2002). A communication system "maps external forms (such as speech sounds or manual signs), via mental structures, to meanings (where many, if not all, meanings relate to external objects, events or situations)" (Hurford 2002: 312). This mapping is subject to constraints of real time and linearization. What may well serve the purpose of representing thought may place a burden on speech perception and production and conversely, facilitation of communication may be in conflict with facilitation of meaning representation.

That grammar has its own primitives whereby the link between form and conceptual structure as well as the speakers' communicative needs is not perfect is well known and has been illustrated in the literature with examples of meaningful sentences that can be grammatical or ungrammatical depending on the language (1), semantically deviant sentences that are nevertheless grammatical (2), as well as sentences that are both grammatical and meaningful but that are uninformative (3): ${ }^{3}$

(1) a. English: SVO (Neeleman and Weerman 1997) that John read the book. '*that John the book read.'

b. Dutch: SOV (Neeleman and Weerman 1997)

dat Jan het boek las. that John the book read 'that John read the book.'

(2) \#If someone is here, then no one is here.

(3) John is similar to himself.

3 Throughout, ungrammaticality is indicated with the star $\left.{ }^{*}\right)$; semantic deviance is indicated with the \#-sign. 
The structural properties of the English sentences in (1)-(3) do not follow from semantics and the context of communication. The fact that English is an SVO language while Dutch is SOV is not a semantic fact: the grammatical English and Dutch examples have the same semantic analysis. What (2) and (3) demonstrate is that the grammar makes it possible for speakers to produce and process incoherent sentences as well as sentences that are of no or little use to them in communication.

Moreover, while the thoughts that underlie sentences are unambiguous (even if they are general and vague), ambiguity is rampant in language (at all its levels), which is illustrated with the example in (4), originally due to Chomsky (cf. also Hurford 2002): ${ }^{4}$

(4) Mary saw the man leaving the store.

The example in (4) is three-ways ambiguous. To the extent that the grammar can help resolve the ambiguity by providing three different structures for the three distinct interpretations, it can be seen as an optimal instrument for conveying meaning, but it evidently places a burden on speech perception in verbal communication.

On the assumption that syntactic structure is designed for providing mental structures underlying thought, all syntactic structure must be inherently meaningful. However, language provides ample evidence that the relation between syntax and semantics is not isomorphic. For example, the semantic representation of sentences describing the same situations is the same regardless whether the language marks subject-verb agreement or not and whether it marks case and gender morphologically or not. The explanation for the difference in agreement between (5) and (6), both of which can be used to refer to a singular event of piano-lifting or to a plurality of such events in the context of a quantificational adverb like kilka razy 'several times' in Polish, is not rooted in semantic differences and further, the Polish sentences in (5) and (6) below have the same semantic structure as their English equivalents despite the fact that in contrast to English, Polish marks the difference between nominative and genitive case, encodes gender, and has regular as well as default agreement: ${ }^{5}$

$$
\begin{array}{lll}
\text { Czterej mężczyźni } & \begin{array}{l}
\text { podnieśli } \\
\text { four }_{\text {M.PL.NOM }} \text { men }_{\text {M.PL.NOM }}
\end{array} \text { lifted }_{3 . P L . M} & \text { piano }_{\text {N.SG.ACC }} \\
\text { 'Four men lifted the piano.' } &
\end{array}
$$

4 Hurford (2002) illustrates ambiguity in phonology with plosives which are phonetically voiced or voiceless in contexts where voicing commences simultaneously with release, as in beer and spear. So-called bracketing paradoxes (e.g. [[moral] [philosopher $]$ ] vs. [[moral] [philosophy]er $]]$ ) are instances of ambiguity in morphology. Multiplicity of meaning (polysemy and homonymy) are well known in semantics (e.g. mouse applies both to an animal and to a computer device, modal auxiliaries can express both epistemic and deontic modality etc.). Ambiguity also characterizes speech acts, e.g. Can you meet us? can be interpreted as a question or a request.

${ }_{5}$ In Polish, if the quantified noun is in the genitive, agreement defaults to $3^{\text {rd }}$ person singular neuter. 
(6) Czężżczyzn podniosło pianino.

four $_{\text {M.PL.NOM/GEN }}$ men $_{\text {M.PL.GEN }}$ lifted ${ }_{3 . S G . N}$ piano $_{\text {N.SG.ACC }}$

'Four men lifted the piano.'

Furthermore, if syntactic and semantic rules are linked, language should not have meaningless elements and syntax should not manipulate them. This prediction is not borne out empirically. For example, English has so-called expletive subjects illustrated in (7) and (8). While expletive there and it have a role to play in ensuring grammaticality, there is no motivation for their presence in the representation of meaning:

(7) a. There is a unicorn in the garden.

b. ${ }^{\star}$ Is a unicorn in the garden. ${ }^{*}$ In the garden is a unicorn.

(8) a. It is five o'clock.

b. ${ }^{\star}$ Is five o'clock.

A strong argument for the independence of form from function (meaning) can be provided if it can be shown that the syntactic operations that build semantically different structures obey the same formal principles. If there exist formal principles that constrain structure-building that are de-linked from the meanings that the structures encode, syntactic structures cannot be functionally motivated. One such formal construct that constrains structure-building in generativist models of language is c-command. This notion has been introduced to define the domain in which syntactic rules operate and in which grammatically-determined dependencies hold. For example, English has elements like any, which require licensing from some negative element in the structure, as illustrated in (9) from Smith (2002: 347-348):

(9) a. John ate something/some salad.

b. ${ }^{\star} J o h n$ ate anything/any salad.

c. John didn't eat anything/any salad.

The constraints on the distribution of elements like any, called Negative Polarity Items (NPIs), are quite intricate. As shown in (10), an NPI and its licensor may occur in distinct clauses. Furthermore, for an NPI to be licensed, the licensing element must be structurally 'more prominent' rather than simply precede the NPI in the structure, as is shown in (11):

(10) I don't think he has eaten anything.

(11) a. Nothing will change anything.

b. ${ }^{\star}$ That nothing has happened will change anything.

c. ${ }^{\star}$ The fact that he hasn't come will change anything. 
'Structural prominence' that plays a role in determining the licensing condition on the distribution of NPIs in English is provided in (12) and illustrated in (13) below:

(12) a. A c-commands B if and only if A does not dominate B and the first branching node dominating $\mathrm{A}$ also dominates $\mathrm{B}$.

b. A dominates B if B is a constituent of $A$.

(13)

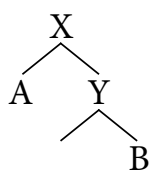

In the tree in (13), the first branching node dominating $\mathrm{A}$, which is labeled $\mathrm{X}$, also dominates $\mathrm{B}$ and therefore, $\mathrm{A}$ c-commands $\mathrm{B}$. B does not c-command $\mathrm{A}$, as the first branching node over B, labeled Y, does not dominate A. The NPI anything is licensed in (9c), (10) and (11a), because the negation-bearing elements c-command anything: both the morpheme of negation and the subject of a sentence c-command the object. The NPI is not licensed in (9b), as there is no negative licenser. It is not licensed in (11b) and (11c), because the negation-bearing elements are both in the embedded clause while anything is in the main clause and hence is not c-commanded by a negative element in these contexts. The difference between (11a) on the one hand and (11b) and (11c) on the other hand suggests that the crucial notion that plays a role in the distribution of NPIs in English is not precedence. Thus, the generalization is that an NPI must be c-commanded by negation to occur in a syntactic structure.

In fact, NPIs are not restricted in their distribution to negative contexts. Other contexts in which NPIs can occur in English are shown in (14). What negative, interrogative and conditional sentences have in common is that they are so-called opaque domains, i.e. grammatical contexts which have an effect of creating (scope) ambiguity.

(14) a. Did John eat anything?

b. If John ate anything, I'd be amazed.

To the extent that there is a semantic invariant that characterizes negative, interrogative and conditional sentences, the distribution of elements like anything could be claimed to be meaning-related and offered a uniform explanation in the semantics. Namely, the distribution of NPI depends on the presence in the structure of an operator that interacts with the existential operator in the semantic structure of an indefinite NPI. In this situation, a strong case could be made for a close link between form and meaning. However, c-command constrains other, semantically unrelated grammatical phenomena which do not involve ambiguity-creating operators, for example the distribution of reflexives and coreferential pronouns. 
As shown in (15), a reflexive must pick its reference form an antecedent in the syntactic structure in which it appears. ${ }^{6}$ A personal pronoun cannot have an antecedent in the same context. The conditions on what counts as the domain in which the reflexive must pick its reference and the pronoun must be free (non-coreferential) are quite intricate:

(15) a. ${ }^{\star}$ Himself $_{\mathrm{i}}$ will come.

b. $\mathrm{He}_{\mathrm{i}}$ will come.

c. John ${ }_{\mathrm{i}}$ distrusts himself ${\mathrm{i} / \mathrm{j}^{\mathrm{j}}}$.

d. John ${ }_{\mathrm{i}}$ distrusts him ${ }_{*_{\mathrm{i} / j}}$.

e. ${ }^{*}\left[\right.$ John's $_{\mathrm{i}}$ sister] distrusts himself . $_{\mathrm{i}}$

f. [John's sister] distrusts him . $_{\mathrm{i}}$

The contrast between (15c) and (15d) shows that a reflexive must be c-commanded by its antecedent while a pronoun must be free in the same syntactic context. In (15e), the NP2 John does not c-command the reflexive, because it is embedded in the subject NP-node (NP1) and NP1, which is the first branching node above the NP2 John, does not dominate himself. As the reflexive is not c-commanded by the expression it is co-indexed with, it cannot pick the same individual as the NP John picks and lacking an antecedent, it cannot be interpreted:

(16)

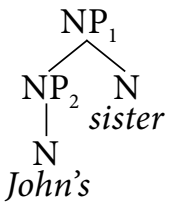

Also pronouns cannot pick their referents from $\mathrm{r}$ (eferential)-expressions like John, the boy etc., as demonstrated in (17). Crucially, a pronoun can be co-indexed with an r-expression as long as it does not c-command the r-expression:

(17) a. ${ }^{\star} \mathrm{He}_{\mathrm{i}}$ distrusts $\mathrm{John}_{\mathrm{i}}$.

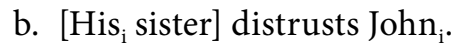

Wrapping up, the distribution of distinct formal elements in semantically and functionally disparate structures is constrained by the same structural relation of c-command. This is evidence that structural principles are independent of semantics and discourse function. ${ }^{7}$ Notice that c-command is an abstract formal notion that

6 Coreference is captured with co-subscripts. Coreferential elements are elements which refer to the same individual. Elements with distinct subscripts do not refer to the same individual.

7 There are other grammatical phenomena that have been explained with the help of c-command. For example, c-command plays a role in determining the interpretation of a pronoun as unbound (roughly, picking its referent from discourse) or as bound as a quantifier. For a pronoun to be interpreted as bound by a quantifier, the pronoun must not c-command the position from which the quantifier moves, which is the position occupied by the unpronounced who and whose in (i) and (ii), respectively (cf. Chomsky 1995: 73-74). As a result, (i) has the semantic 
cannot be learned: the crucial evidence that could lead a child into formulating the right hypothesis about the distribution of NPIs and about the conditions on nominal reference is negative. Negative evidence in the form of ungrammatical sentences is missing from the data available to the child.

In functionalist literature, the argument that semantic and culture-specific concepts shape the grammars of human languages is often made with respect to linguistic categorization. Both lexical and syntactic categories are typically associated with particular kinds of semantic content and/or discourse functions. For example, Hopper and Thompson (1984) argue that the lexical categories of noun and verb are universal and that they encode the concepts of "discourse-manipulable participant" and "reported event", respectively. In their view, "categoriality itself is another fundamental property of grammars which may be directly derived from discourse function" (Hopper and Thompson 1984: 703). Conventional and culturespecific semantics has also been argued to play a crucial role in noun classification, i.e. assignment of nouns to classes (cf., among others, Wierzbicka 1985, Lakoff 1987, Corbett 1991). Commonly recognized distinctions on which noun classification is based include notions such as [animate/inanimate] [human/non-human] and [male / female]. This differentiation is extralinguistic, but to the extent that such oppositions are systematically reflected in the morphosyntax of languages, they are the basis of linguistic classification. Although one could analyze features such as [ \pm animate] as semantically based formal features, in the functionalist literature such oppositions are often claimed to be directly rooted in the speakers' conceptualization of nominal referents. On this view, linguistic distinctions are conceptual distinctions that determine the structure of language.

A consequence of taking purely semantic or conceptual categories to drive the classification of nouns is that the conceptual boundaries between noun classes must sometimes be stretched to a point where the postulated classes do not have a conceptual reality. This can be shown both with respect to fairly well-established as well as to exotic classifications. For example, Polish is traditionally analyzed to have masculine, feminine and neuter genders. Nouns classified with masculine gender fall into three subclasses: human, animate and inanimate. The [+ animate] category encompasses nouns referring to animals, e.g. byk 'bull', but it also includes inanimate nouns like papieros 'cigarette'. The [- animate] subclass includes mainly nouns with inanimate referents, e.g. plecak 'backpack'. However, some collective nouns, which are nouns with "dual personality" in language, are also grammatically inanimate masculine nouns. Examples include chór 'choir', zespót 'team / band', etc. The grammatical status of such nouns remains the same regardless whether they denote so-called group atoms that lack internal structure on a par with other

structure in (iii) and (ii) is has the semantic structure in (iv). Crucially, the pronoun cannot have the bound reading in (iv):

(i) Who [ said he admires John's father]?

(ii) Guess whose father [they said he admires whose father].

(iii) For which person $\mathrm{x}$ [x said $\mathrm{x} /$ he admires John's father]

(iv) For which person $x$ [they said he admires x's father] 
individual-denoting nouns or they have pluralities of members (and hence internal structure) in their denotation. On the latter interpretation, such nouns are notionally plural when in the singular and they are notionally animate rather than inanimate, which is why they can combine with number and / or animacy-sensitive predicates, as shown in (18) below:

(18) Chór SG $_{\text {zebrał się }}$ SG $/$ wystąpił $_{\mathrm{SG}} \mathrm{w}$ niedzielę w katedrze.

'The choir met / performed in the cathedral on Sunday.'

The analysis of noun classifications in less familiar languages has sometimes resulted in exotic categorization based on complex, culture-specific notions generally not represented in other natural language grammars. A well-known example is the noun classification in Dyirbal, a Pama-Nyungan language of Australia, made famous for placing 'women', 'fire' and 'dangerous things' in the same category, which Lakoff (1987) argued to be conceptually motivated, reinterpreting Dixon's taxonomy provided in (19) from Lakoff (1987: 92-93) in prototype-theoretic terms:

(19) Dixon's account of the distribution of concepts across noun classes in Dyirbal

I: (human) males; animals (e.g. men, kangaroos, most snakes, most fishes, the moon, storms, some spears, etc.)

II: (human) females; water; fire; fighting (e.g. women, dogs, most birds, fireflies, scorpions, crickets, the hairy mary grub, anything connected with water or fire, sun, stars, etc.)

III: non-flesh food (e.g. all edible fruit and the plants that bear them, wine, cake, cigarettes)

IV: everything not in the other classes (e.g. parts of the body, meat, wind, most trees, grass, noises, language, etc.)

In Lakoff's analysis, the marked radial categories are based on complex, culturespecific conceptual associations. Apart form the default category, the central concepts around which the conceptually distinguished categories are built are, respectively, human masculinity, human femininity and plant/non-flesh food. Other nouns are attracted to the class by bearing some conceptual resemblance to the prototypical member, although they do not have all the crucial features of the prototypical member(s). More peripheral members are linked to the prototype via some associative link or links. The result is a radial structure with more prototypical members around the center and less prototypical members located in more peripheral positions in the network. The associative links are established on the basis of some general cognitive principles such as the myth-and-belief, domain-of-experience and important-property principles. For example, the sun is in class II, because it is a female deity married to the moon, which is in class I. Birds are in class II, because they are believed to be spirits of dead women. Also crickets, which are mythically 'old' ladies' are in this class. Women and fire are in the same class, because women are related to the sun via myth and the sun is 
related to fire via domain-of-experience. Stinging and biting creatures are also in this class, because they cause pain similarly to a burn. By association (via the important-property principle), anything that is harmful is placed in this class, too. The resulting prototype-based reinterpretation of the classification in (19) is claimed to have a rational basis and to be based on regular and general principles of human conceptualization.

Apart from leaving the reasons for why for example, water should be in the same class as fire (for while it distinguishes fire, which Lakoff (1987: 100) offers by way of explanation, it is neither female nor dangerous), the account, as observed by Plaster and Polinsky (2007), does not have predictive power and in addition, it raises learnability questions. In particular, it is unclear how children acquiring Dyirbal can acquire its system of noun classification if they initially lack the highly abstract and culture-specific information crucial for the assignment of individual nouns to their classes. By carefully considering the form that Dyirbal nouns have and by looking at diachronic evidence relating to the development of Dyirbal noun classification, Plaster and Polinsky are able to show that the modern Dyirbal noun classification is based on a small number of coherent semantic features, including [ \pm animate], [ \pm female], $[ \pm$ edible], which provide the semantic underpinnings for classes I-III, class IV being the default gender. That nouns that lack such semantic features in their lexical entries are assigned to their respective classes finds an explanation in two factors of a formal nature. According to Plaster and Polinsky (2007: 14), noun classification in Dyirbal is a fairly recent development from a classifier system in which there were many distinct classifiers. While the classifiers may have had coherent semantic underpinnings, when numerous semantically unrelated classifiers merge into a few genders (based on shared formal features or by accident), the resulting noun classes need no longer correspond to coherent conceptual categories and nouns may be attracted to a given class based on formal rather than conceptual-associative principles. For example, Plaster and Polinsky argue that (certain) nouns relating to fire and water were assigned to class II not by association with females, which by myth-and-belief were associated with the sun, with fire attracted to the class via the domain-of-experience principle, attracting water perhaps by antithesis or as being associated with its fire-distinguishing characteristic by the important-property principle, but rather, by formal clues such as the phonological shape of the left or right edges of words in Dyirbal (bugan 'brush fire' ends in - gan, which is formally identical with the feminine suffix -gan; binda 'waterfall' begins with $b i-$, which is the initial sequence of many words in class II, including bima 'death adder' as well as the English borrowing bigi 'pig', expected to be in class I, the default gender for animates, on Dixons and Lakoff's accounts; garri 'hairy mary grub' is identical in form to garri 'sun'; garram 'garfish' is in class II because its phonological left edge is the same as in garri, etc.). The resulting taxonomy is much less exotic than either Dixons' classification or Lakoff's reinterpretation of it. In Plaster and Polinsky's account, Dyirbal noun classification is similar to the noun classes in the languages studied by Corbett (1991): it is partly semantic and partly formal in nature. The semantic features are the familiar features found in other languages ([male], [female], 
[animate], [edible]). ${ }^{8}$ The formal features are phonological. They are the initial syllables $b i$-, $g u g u-, m a$ - and $y i$-, which are stressed and hence prosodically prominent in Dyirbal, attracting the attention of a child acquiring the language. The formal features also include at least one salient suffix (-gan). ${ }^{9}$ Acquiring such a language should present no more problems to children lacking the culture-specific concepts and complex associative relations that hold across a class than acquiring other existing and less 'exotic' noun classifications.

In the next section, I will discuss some arguments raised in support of the claim that grammars are shaped to facilitate externalization of thought in communication.

\section{Formal properties of language and the pressure for efficient use of language in communication}

Among the external functional pressures that are taken to have shaped formal grammar are principles that favor simpler and faster processing. Human processing is remarkably fast and efficient: "every word has to be picked from the ensemble of 50,000 , identified in one third of a second, and put in the right structure" (Newmeyer 2001: 585). Among the functional principles that constrain the construction and interpretation of syntactic structure in the interests of more effective processing are principles that reduce recognition domains and facilitate the flow of information in discourse (Newmeyer 2001, Culicover and Jackendoff 2005).

The former have been held responsible for the tendency of VO languages to have prepositions and OV languages to have postpositions, a well-known typological generalization. A functionalist explanation why languages that have $\mathrm{VO}$ order tend to have prepositions and that languages with OV order have postpositions is that such orders are natural and easy to parse (cf. Baker 2001, Newmeyer 2001). This is because the recognition domain for the verb phrase (VP) is shorter compared to other logically possible orders. In (20a) and (20b), the verb (V) and the preposition (P) as well as $\mathrm{V}$ and the postposition (Po) are separated only by one constituent, the object NP. In (20c) and (20d), the distance between V and P is longer, as it also includes the complement of the postposition $(\mathrm{Po})$ and preposition $(\mathrm{P})$, respectively:
a. VO-and-prepositional: [ $\left.{ }_{\mathrm{VP}} \mathbf{V ~ N P}\left[{ }_{\mathrm{PP}} \mathbf{P} \mathrm{NP}\right]\right]$
b. OV-and-postpositional: [VP NP V [ $\left.{ }_{\mathrm{PoP}} \mathrm{NP} \mathbf{P}_{\mathbf{o}}\right]$ ]
c. VO-and-postpositional: [ ${ }_{\mathrm{VP}} \mathbf{V ~ N P}\left[{ }_{\mathrm{PoP}} \mathrm{NP} \mathbf{P}_{\mathbf{o}}\right]$ ]
d. OV-and-prepositional: $\quad\left[{ }_{\mathrm{VP}}\left[{ }_{\mathrm{PP}} \mathbf{P} \mathrm{NP}\right] \mathrm{NP}\right.$ V]

As reported in Baker (2001: 82), OV-and-prepositional languages are rare among the languages of the world. They constitute only $6 \%$ of the total of OV languages

8 Plaster and Polinsky (2007) acknowledge the existence of minor semantic subclasses, including [+ fire].

9 See Corbett (1991: 33-69) for a discussion of the role that morphology (e.g. suffixes) and phonology (e.g. stress) play in determining noun/gender classification in natural language. 
(in a sample of over 1,000 investigated languages). Amharic, which is an OV-andprepositional order language, was originally a VO language, but borrowed the OV order from neighboring Cushitic languages while retaining prepositions (Newmeyer 2001). According to Newmeyer, this resulted in a structural disharmony and decreased parsing efficiency. However, if the orders in (20c) and (20d) were dispreferred for reasons of the efficiency of processing, such languages would be dysfunctional and more difficult to acquire and process. There is no evidence that such languages pose more problems in processing and acquisition compared to the better behaved languages with the orders in (20a) and (20b). It may very well be that the reasons why languages with the properties in (20c) and (20d) are crosslinguistically rare are purely formal rather than functional in the sense described above. In generative grammar, the ordering of constituents is determined under the general head directionality parameter. The operation that merges constituents into a phrase can merge a head element with its complement. The relative ordering of the two syntactic objects is left open by UG: heads may be initial or final in a phrase. Parameters account for language variation, but logically speaking, if the head directionality parameter is set for all heads, the grammar is more parsimonious. Languages with the orders in (20c) and (20d) may be rare for the simple reason that they occur only if two distinct head-complement orders, each specified for a choice of heads, come together. This situation may be statistically less frequent than the situation in which all heads are either initial or final. If this is on the right track, the real explanation for the rarity of VO-and-postpositional and OV-and-prepositional orders may well lie in statistical principles. This explanation, provided in terms of the head directionality parameter, a primitive of grammatical structure, may be more informative than a surface-oriented implicational universal.

If natural language grammar were made to facilitate processing, human languages should not have their characteristic property, namely displacement. Consider the following example from Chomsky (2007: 22):

\section{(21) What did John eat?}

The pronoun what in (22) above has two interpretations; it is the focus of the sentence and at the same time, it is the semantic argument of the verb, interpreted as the object. However, it does not occur in the structural position usually occupied by objects. The object position is missing or empty, which is why it is often referred to as a gap. The $w h$-pronoun is interpreted as the filler for the gap. In other words, the gap must be identified and filled with the missing element when the sentence is processed. This is a processing burden: an element is interpreted in one position and it is pronounced in another. This does not make much sense form the point of view of processing ease. Nevertheless, to achieve a coherent interpretation at the semantic interface, what must be moved away from the position in which it receives its semantic role. The reason is that what is operator-like and must take scope over the entire clause. In other words, what is interpreted in sentence-initial position as an operator. To be interpreted for its semantic role as the argument of the verb 
in the object position, what must leave a copy in the position from which it moves. The copy that it leaves behind in object position is interpreted as the variable that restricts the operator. The structure built in the course of the syntactic derivation shown in (22) can be assigned the semantic interpretation in (23) at the interface level at which linguistic representations of meaning are determined. The copy, interpreted as the restricted variable in (23) is the crossed out constituent in (22):

(22) [What [did [John eat what]]]

(23) [For which $\mathrm{x}, \mathrm{x}$ a thing [John ate $\mathrm{x}]]$

Notice that the element that moves in the syntax leaving a copy behind is pronounced in only one position. This may be argued to fall from the principles of efficient computation, as pronouncing both occurrences of the same element would add to computational complexity in the phonetic component. At the same time, the necessity of finding and filling the gap adds to complexity in speech perception, as form does not unambiguously align with meaning.

In fact, phonological structures that are generated at the phonetic interface level often do not correspond to syntactic phrases and do not align with semantic units. This sheds some doubt on the idea that linguistic structure is shaped by external functional pressure for form and meaning to be aligned, as such alignment can facilitate processing (cf. Newmeyer 2001). For example, the prosoding bracketing (25) suggested for the sentence in (24) does not map isomorphically onto the syntactic bracketing of (24). Neither does the prosodic bracketing align with the semantic bracketing: Sesame Street is a production of is not a semantic unit (cf. Jackendoff 2003: 656):

(24) [Sesame Street [is [a production [of [the Children's Television Workshop]]]]]

(25) [Sesame Street is a production of] [the Children's Television Workshop]

The displacement property of natural language grammars, illustrated with the movement of what in (21) is an unexpected property of language as it is clearly at odds with the interests of processing efficiency. At the same time, the displacement of what gives the right results on the semantic side of language. However, the grammar of natural language has ways to interpret what as an operator binding a variable that restricts its range even when what does not move in the syntax. A quasi-operator like what can remain in situ, the position in which it is merged in the syntax as the complement of the verb and in which its semantic role is interpreted in some languages, for example Chinese (Boeckx 2006: 44):

\footnotetext{
Zhangsan mai-le shenme?

Zhangsan buy-past what

'What did Zhangsan buy?'
} 
On the assumption that shenme is a quasi-operator in Chinese just as what is in English and that the semantic structure of the Chinese question in (26) and its English counterpart is the same, the quasi-operator must be dislocated at the level in which the grammatically relevant aspects of meaning are determined. This invisible movement, resulting in a structure analogous to (22), is necessary for the right representation of meaning, i.e. for (26) to be assigned the interpretation for which $x, x$ a thing, Zhangsan bought $x$ (cf. (23)). Although it creates a gap that requires filling in the semantics, the invisible movement is more economical in that it does not pose a burden in speech production and perception. Why should Chinese but not English facilitate communication? The reason could be that some feature, e.g. [+ wh], must end up in some dedicated position on the left edge of a clause in some languages (English) but not others (Chinese) because the uppermost syntactic head in a clause $(\mathrm{C}, \mathrm{CP})$ requires some lexical material in its specifier, attracting the $[+w h]$ element, to be licensed in the syntax or perhaps, because it is a formal feature that must be eliminated from the derivation before the structure is sent-off to the semantic interface in some languages (English) but not in others (Chinese).

Another functional principle that has been argued to shape formal grammars in the interests of more effective processing is the discourse-related principle responsible for the occurrence of the element attracting the listener's attention in sentence-initial position. For example, DeLancey (2001) rejects the possibility that displacement to sentence-initial position can be triggered by some formal property of the construction (e.g. the presence of a formal feature like [+ F(ocus)] or [+ Top(ic)] on an element that triggers movement in the syntax), offering an explanation based in the principles of human psychology. Accordingly, the element attracting attention is placed sentence-initially, because "the first in a series - any kind of series, in any modality - has the perceptually privileged position" (DeLancey 2001: 5).

The observation that left edges are perceptually salient is obviously true, but the question that arises is whether this means that information structure is directly encoded in syntax. If it is, we expect to find in syntactic structures a syntactically represented position dedicated to hosting this element of the structure that attracts increased attention in verbal communication. The elements that receive increased attention are typically focal elements, which are prosodically prominent (accented). However, as observed by Fanselow $(2006,2008)$, the elements moved away from the positions in which they are interpreted for their semantic role, e.g. as object, need not correlate with the focus of the sentence. For example, the phrase einen Schrank 'a cupboard' can express narrow (NP) focus or wide (VP) focus) in (27) below. In response to the question 'What did you paint?', einen Schrank expresses narrow focus. The question 'What did you do last Sunday' triggers VP-focus interpretation of the response:

$$
\begin{aligned}
& \text { Einen Schrank hab ich lackiert. } \\
& \text { a cupboard have I painted } \\
& \text { 'I painted a cupboard.' }
\end{aligned}
$$

On the VP-focus interpretation the phrase einen Schrank fronted in (27) above is not the focus of the utterance. Rather, it is smaller than the focus. As a fronted phrase 
can also be larger than the focus, e.g. when a prepositional phrase moves, but only the complement of the preposition is the focus, as shown in (28), a potential answer to the question 'What did he do?', Fanselow $(2006,2008)$ links displacement to accent attraction.

(28) Unter der Brücke hat er geschlafen. under the bridge has he slept 'He slept under the bridge.'

In this scenario, focus movement can be analyzed as a special case of accent attraction. If correct, what this shows is that syntax does not interact directly with information structure (at least with respect to focalization). Contrary to the functionalist explanation suggested by DeLancey (2001), formal grammar is not shaped by the distribution of focus, a discourse-related property. Rather, the relation between syntactic structure and information structure is indirect: information structure interacts directly with prosody and prosody is relevant for syntactic computation (and also has semantic and/or pragmatic effects). In this scenario, there is no need to postulate that focused sentenced are distinguished from sentences with neutral information structure in terms of syntactic structure.

\section{Conclusion}

The aim of this paper was to compare how certain grammatical phenomena have been analyzed in the generativist and functionalist approaches to language. Functional analysis is impressed by the close relation of language to semantics, socially and culturally-determined conceptualization, pragmatics and other extra-linguistic factors that play a role in communication. Generativist analysis does not deny the importance of such factors for the design of language, but it is impressed by the structural complexity of language and questions of learnability.

In the recent framework of the generative grammar, which takes language to be optimally designed to meet the demands of the external interfaces, grammatical principles are taken to be partly motivated by language-external principles: the human mind can only cope with certain sensory data and process certain meanings. The structures that syntax generates must be usable in the components in which the articulated form of the sentence and its representation of the meaning are computed. As a coding system linking between the space of sound and the space of meaning, language is also under pressure for computational efficiency. When the demands are in conflict, the grammar chooses to place the burden on communication.

I have looked here at a number of grammatical phenomena mainly, but not only, in reference to English. What the discussion suggests is that an abstract, indepth analysis that takes into consideration also the formal properties of language stands a better chance of contributing insight into the principles of language than an analysis which disregards the importance of form in language. 


\section{References}

Baker M. 2001. The atoms of language. New York.

Boeckx C. 2006. Linguistic minimalism. Oxford.

Carruthers P. 2002. The cognitive functions of language. - Behavioral and Brain Sciences 25: 657-726.

Chomsky N. 1995. The minimalist program. Cambridge.

Chomsky N. 2005. Three factors in language design. - Linguistic Inquiry 36: 1-22.

Chomsky N. 2007. Of minds and language. - Biolinguistics 1: 19-27.

Corbett G. 1991. Gender. Cambridge.

Croft W. 1995. Autonomy and functionalist linguistics. - Language 71: 490-532.

Culicover P., Jackendoff R. 2005. Simpler syntax. Oxford.

DeLancey S. 2001. On functionalism. [LSA Summer Institute, Santa Barbara, Lecture Notes (Lecture 1) <http:/www.uoregon.edu/ delancey/sb/LECT01.html >]. Santa Barbara.

Fanselow G. 2006. Pure syntax. - Brandt P., Fuss E. (eds.) Form, structure and grammar. Berlin: $137-158$.

Fanselow G. 2008. In need of mediation: the relation between syntax and information structure. - Acta Linguistica Hungarica 55: 1-17.

Hopper P., Thompson S. 1984. The discourse basis for lexical categories in universal grammar. - Language 60: 703-752.

Hurford J. 2002. The roles of expression and representation in language evolution. - Wray A. (ed.) The transition to language. Oxford: 311-334.

Jackendoff R. 2003. Précis of 'Foundations of language: brain, meaning, grammar, evolution'. Behavioral and Brain Sciences 26: 651-707.

Lakoff G. 1987. Women, fire, and dangerous things. Chicago.

Neeleman A., Weerman F. 1997. L1 and L2 word order acquisition. - Language Acquisition 6: 125-170.

Newmeyer F. 2001. Where is functional explanation? - Chicago Linguistic Society 37: 583-599.

Newmeyer F. 2003. Grammar is grammar and usage is usage. - Language 79: 682-707.

Plaster K., Polinsky M. 2007. Women are not dangerous things: gender and categorization. Harvard Working Papers in Linguistics 12: 1-44.

Smith N. 2006. History of linguistics: discipline of linguistics. - Brown K. (ed.) The encyclopedia of language and linguistics. Amsterdam: 341-355.

Wierzbicka A. 1985. 'Oats' and 'wheat': the fallacy of arbitrariness. - Haiman J. (ed.) Iconicity in syntax. Amsterdam: 311-432. 